\title{
センサネットワーク概観
}

正 員 井家上哲史*

\section{An Overview of the Sensor Networks}

Tetsushi Ikegami*, Member

Recently, the sensor network technology attracts a great deal of attention achieving a safe and comfortable ubiquitous society. The sensor networks are already used in environment and disaster monitoring, medical care, logistics and transportation.

This paper aimed to understand the outline of the sensor network technology centering on the wireless sensor network technology.

キーワード : センサネットワーク，ユビキタス，ZigBee，UWB

Keywords : sensor network, ubiquitous, ZigBee, UWB

\section{1. はじめに}

近年，安心・安全・快適なユビキタス社会の実現に向け センサネットワーク技術が注目を集めている。センサネッ トワークは，様々な構造物・環境・生体などで発生する膨 大な情報を大量のネットワーク化されたセンサ端末を分散 配置することで収集する。すでに, 環境計測, 医療・福祉, 防災，商品流通，交通などなど様々な分野で利用されてい る。今後，さらに研究開発，標準化の進展により急速な普 及が期待されている。そうした中, 各年代での技術の総括 と方向性の明確化が重要である ${ }^{(1)(2)}$ 。電気学会においては, 2005 年から 2 年間にわたり，センサネットワーク調査専門 委員会において，センサネットワークに関する多様な要素 技術の現状と，適用が期待される産業分野についての調査 及び，各方面への適応想定並びにその効果，解決すべき技 術的課題などを検討し，この技術の将来像を予測し，また 研究開発の指針を明らかにすることを目的とした調査活動 を行い，技術報告「センサネットワークの技術動向と最新 事例」 ${ }^{(3)}$ によめた。

本稿は，文献 $(3$ ) を中心に，センサネットワーク技術の 概要を理解していただくことを目的とした。

\section{2. センサネットワークの適用領域}

現在，様々な分野にセンサネットワークを導入すること が試みられている。図 1 に計測領域と移動量を軸としてセ ンサネットワークの適用領域の分類を試みた。

$\langle 2 \cdot 1\rangle$ 狭域 ·固定 省エネ・省力化を目的としてオ

* 明治大学理工学部

干214-8571 神奈川県川崎市多摩区東三田 1-1-1

School of Science and Technology, Meiji University

1-1-1 higashi-mita, tama-ku, kawasaki-shi, Kanagawa 214-8571

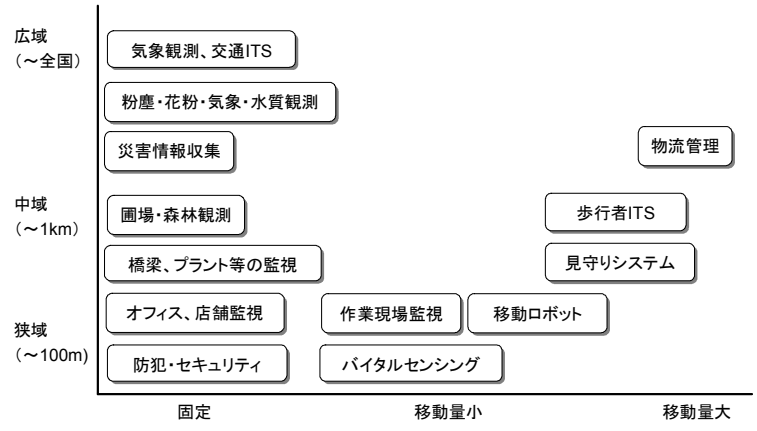

図 1 センサネットワークの適用領域

フィス，店舗における室内環境計測一適用されている。多 数のセンサにより室内環境を計測することで, 冷房機器や 冷蔵機器をきめ細かく制御しようとするものである。また, 計測と制御を連携させることで省力化を図ることができる。 オフィスや住宅での侵入センサや煙探知機からの情報を収 集する防犯・セキュリティシステムも普及している。 オフィス，店舗，住宅については既設設備に対する設置の 容易性の点で無線センサネットワークが適用されることが 多い。

〈2・2〉 狭域・移動量小 センサノードの移動を伴う 例として，在宅もしくは施設内での健康管理を目的として， リアルタイムに脈拍, 血圧などの生体情報を収集するバイ タルセンシングシステムや原子力施設での安全な作業を支 援する放射線可視化システム，家庭用サービスロボットの 例がある。移動を伴うシステムでは移動に支障が無いよう に無線センサネットワークが用いられる。図 2 は放射線可 視化システムの例であり, 固定式検出器モジュール, 移動 式検出器モジュールで計測した放射線量をセンサネットワー ク端末で収集する。無線の到達距離を補うためには中継器 


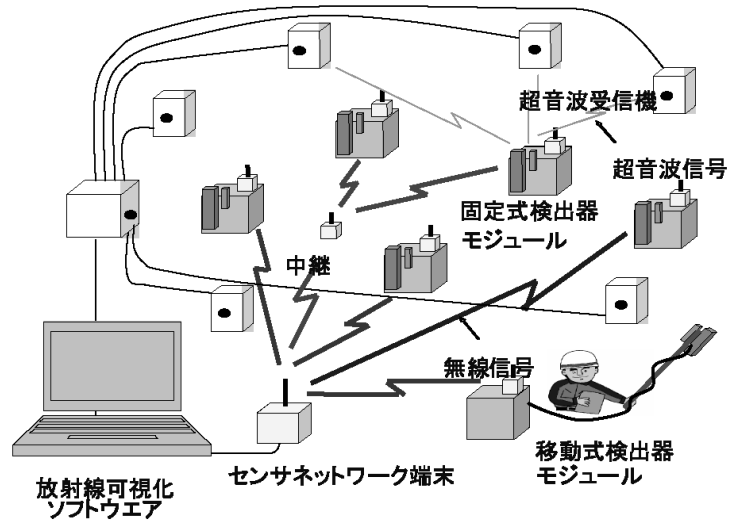

図 2 放射線可視化システム構成概念図

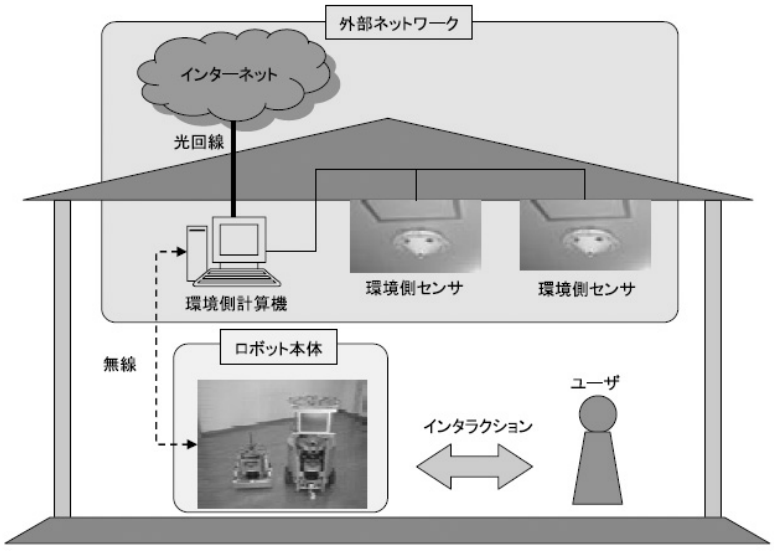

図 3 ネットワーク活用型ロボットシステムの概要 (出典 : 関西電力 R\&D NEWS Kansai, 434 号, pp.16(2006))

が用いられることもある。このシステムではセンサノード の位置検出には超音波による計測システムを併用している(3)。

図 3 はネットワーク活用型ロボットの例であり，単体の ロボットでは電源，計算処理能力が限られているため，知 覚機能をロボットに設置されるセンサと外部サーバに分離 することで高機能化を可能にするものである。

〈2·3〉 中域・固定 2005 年の愛知万博における万博 アメダスでの実証実験，圃場（ほじょう）・森林観測のため のセンサネットワーク実験などが行われている。圃場（ほ じょう)・森林観測とは水田，畑，森林などの日射量，気温， 湿度，土壤水分， $\mathrm{CO}_{2}$ 濃度，物の生育状況をモニタするもの である(4)。

中域・固定の領域では，設置の容易性から無線センサネッ トワークが用いられることが多い。万博アメダスではおよ そ $1 \mathrm{~km}$ 四方の会場内 20 箇所に設置した無線センサ端末が設 置され，多数の無線センサ自身が情報をバケツリレーする マルチホップネットワーク技術によってエリア全体をカバー する構成がとられた。

中域・固定の領域については，光ファイバセンシング技 術を用いたシステムも実用化されている。図 5 はNTT が開 発・実用化した BOTDR (Brillouin Optical Time Domain Reflectometer) を用いた光ファイバ歪み計測装置の適用例で

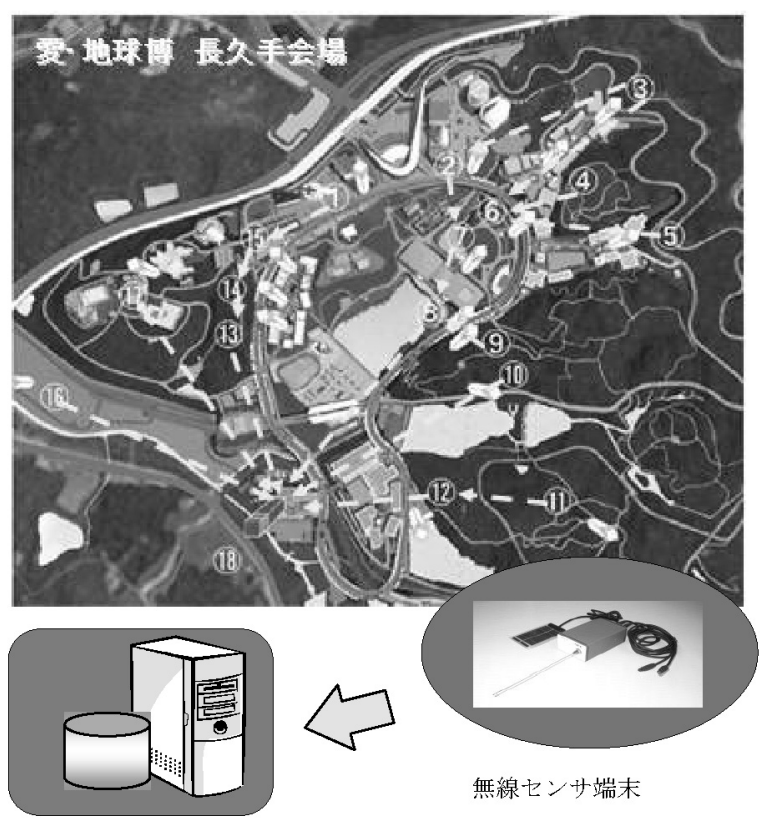

センターサーパ

図 4 万博アメダスのセンサネットワーク構成 (出典 : http://www.nec.co.jp/effort/ubiquitous/2005_0819/)

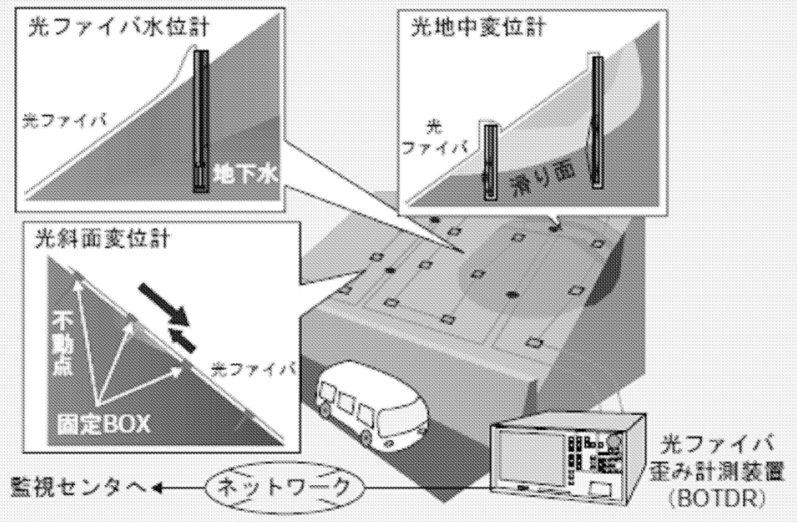

図 5 光ファイバセンサの例

ある(5)。BOTDR は光ファイバに光パルスを入射した時に発 生する後方散乱光を利用して，敷設した光ファイバに沿っ て連続的に歪みを測定することができる。多点の計測を 1 本の光ファイバで実現できる, 計測地点に電源が不要, 落 雷・迷走電流の影響がない，耐腐食・耐湿度性が高い，と いう特長を持ち, 橋梁, 河川, 道路などの監視システムと して使用されている。

〈2·4〉中域・移動 自律移動支援システム (歩行者 ITS (Intelligent Transport Systems)) が歩行者，車いす使用者， 自転車利用者の安全・安心・円滑な移動環境を提供する目 的で開発が進められている。電柱などの障害物の回避情報 などを提供するためには $10 \mathrm{~cm}$ 以内という高精度の測位が必 要であるため, GPS を使用するカーナビゲーションとは別 のシステムが必要とされている。歩行者 ITS を実現する手 段として案内板・標識・視覚障害者誘導用ブロックなどに 


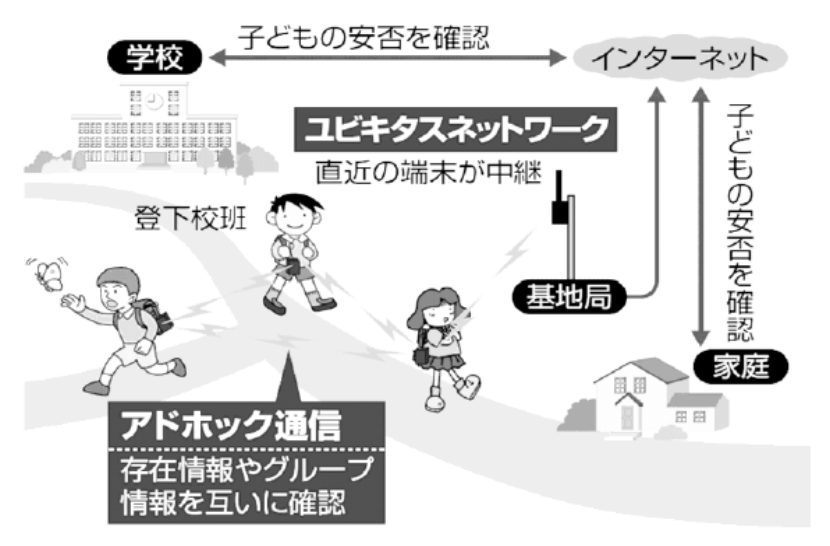

図 6 览童見守りシステムの例

(出典 : www.soumu.go.jp/s-news/2007/pdf /01_sankou/kodomo/05_mimamorisys/r523.pdf)

IC タグを設置する方式や電柱に基地局を設置する方法など が検討されている。

また，社会情勢の変化に呼応して子どもの安全な通学の 確保に対するニーズの高まりから, 総務省の主導により「児 童見守りシステム」が導入され始めている。図 6 は児童見 守りシステムの例であり，子どもに装着した IC タグを利用 して通過地点の履歴や通過時の画像を確認することができ る。

$\langle 2.5\rangle$ 広域・固定 日本全国の気象データを収集す るシステムとしてアメダスが広く認知されている。アメダ スは全国約 1,300 ヶ所の観測所からの気象データを収集して いる。

その他にもより高い密度でセンサを配置することで，地 域に密接した気象情報や災害情報を収集することを目的と

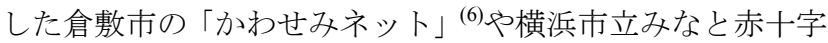
病院アレルギーセンターの粉塵・花粉・気象ネットワーク (7) などがある。交通 ITS としてはカーナビゲーションなどに 渋滞情情報，事故・工事情報などを提供する VICS (Vehicle Information and Communication System) が広く知られている。

広域におけるセンサネットワークの多くはエリアカバー 率の観点から有線ネットワークで構築されているが，PHS 通信を利用した位置検索，運行管理システムもある ${ }^{(8)}$ 。

\section{3. 研究・開発における技術課題}

〈3·1〉 小型・省電カ化 バイタルセンシング，耖童 見守りシステムなどにおいて，センサノードは着用可能= ウェアラブルであることが必須となる。また，小売店鋪の 商品陳列棚などへのセンサノードの設置においても小型化 が要求される。装置の小型化に伴いバッテリの小型化も余 儀なくされるため, 省電力化も必須となる。また，バッテ リ交換が容易でない場所へ設置した場合のメンテナンスの 容易化のためにも省電力化が必要である。

省電力化の手法としては，(1) デバイスのオンオフ制御の 高度化，(2)デバイスそのものの消費電力低減，がある。 デバイスのオンオフ制御の高度化とは，センサネットワー

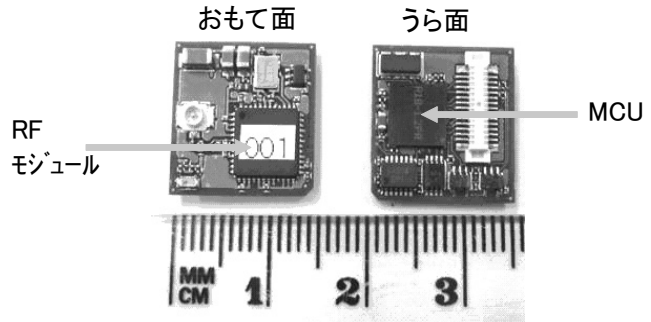

図 7 小型低電力センサネットワークモジュール ZN1 の概観

クのアプリケーションは通信頻度が少ないという性質を利 用して，デバイスの動作時間を短くすることで省電力化を 図る手法である。

センサネットワークでの普及が予想される ZigBee ではセ ンサノード間で同期を取り，送受信タイミングを合わせる ことにより, センサノードの動作時間を最小化するような 動作が可能である。また，日立製作所が開発した小型低電 カセンサネットワークモジュール ZN1（図 7）に採用された 「フローズンスタンバイ」という技術では，待機時の MCU のクロック停止と通信用 LSI の給電停止により低消費電力 化を実現している(9)。さらに, ZN1 ではリアルタイムクロッ クモジュールに低消費電力のチップを採用することで，待 機時電流 $1 \mu \mathrm{A}$ の超低消費電力化を達成している。モジュー ル基板への MCU の実装にも CSP (Chip Scale Package) 技術 を適用して, $15 \mathrm{~mm} \times 15 \mathrm{~mm} \times 4 \mathrm{~mm}$ の小型化を達成している。

〈3·2〉 セキュリティ バイタルセンシング，見守り システム, 物流管理に用いられる電子タグについては, 悪 意のある第三者によって, 漏洩, 偽造／複製, 改竄, 同定 ／追跡，妨害といった务威が想定され，今後の利用拡大の ために十分なセキュリティの確保が課題である。

電子タグのプライバシ確保に関しては，国内では総務省， 経済産業省「電子タグに関するプライバシ保護ガイドライン」 (http://www.soumu.go.jp/s-news/2004/pdf/040608_4_b.pdf) によ り, 電子タグが装着されていることの表示など, 電子タグ の読み取りに関する消費者の最終的な選択権の留保, 電子 タグの社会的利益などに関する情報提供, 電子計算機に保 存された個人情報データベースなどと電子タグの情報を連 係して用いる場合における取扱い，電子タグ内に個人情報 を記録する場合における情報収集及び利用の制限，電子夕 グ内に個人情報を記録する場合における情報の正確性の確 保，情報管理者の設置，消費者に対する説明及び情報提供， が義務付けられている。

その一方で，技術的には表 1 のような対策がとられてい る(3)。表 1 はUHF 帯 RFID (EPCglobal G2/ISO18000-6規格) 及 び ZigBee での対応状況である。ZigBee については ACL (Access Control List) による想定外ノードに対するアクセス 制限, AES-CCM (Advanced Encryption Standard Counter-mode with CBC-MAC) による暗号化通信によりセキュリティが確 保されている。さらに, 暗号化通信を保護するためのセキュ 
表 1 UHF 帯 RFID/センサネットワークでの劦威と対策

\begin{tabular}{|c|c|c|c|}
\hline \multirow[b]{2}{*}{ 脅威 } & \multirow[b]{2}{*}{ 採りうる対策 } & UHF 帯 RFID & \multirow{2}{*}{$\begin{array}{l}\text { センサネッ } \\
\text { トワーク } \\
\text { (ZigBee) }\end{array}$} \\
\hline & & $\begin{array}{l}\text { EPC Global G2/ } \\
\text { ISO18000-6 }\end{array}$ & \\
\hline 漏洩 & リード制限 & $x$ & $\begin{array}{c}\mathrm{O} \\
(\mathrm{CCM})\end{array}$ \\
\hline \multirow{3}{*}{$\begin{array}{l}\text { 同定: } \\
\text { 追跡 }\end{array}$} & データ暗号化 & - & $\begin{array}{c}\mathrm{O} \\
(\mathrm{AES})\end{array}$ \\
\hline & 永久に無効化 & 0 & - \\
\hline & 一次的に無効化 & $x$ & - \\
\hline \multirow[t]{2}{*}{$\begin{array}{l}\text { 偽造/ } \\
\text { 複製 }\end{array}$} & 改ざんを検出 & $x$ & $\begin{array}{c}\mathrm{O} \\
(\mathrm{CCM})\end{array}$ \\
\hline & 複製を防止 & $x$ & $x$ \\
\hline \multirow[t]{2}{*}{ 改ざん } & $\begin{array}{l}\text { ワンタイム書込 } \\
\text { (永久ロック) }\end{array}$ & O & - \\
\hline & $\begin{array}{l}\text { 書込ロック } \\
\text { (パスワードで制限) }\end{array}$ & 0 & - \\
\hline 妨害 & 通信妨害 & $x$ & $x$ \\
\hline
\end{tabular}

ここで, $○:$ サ゚ート, $x$ :未サポート, - : 対象外

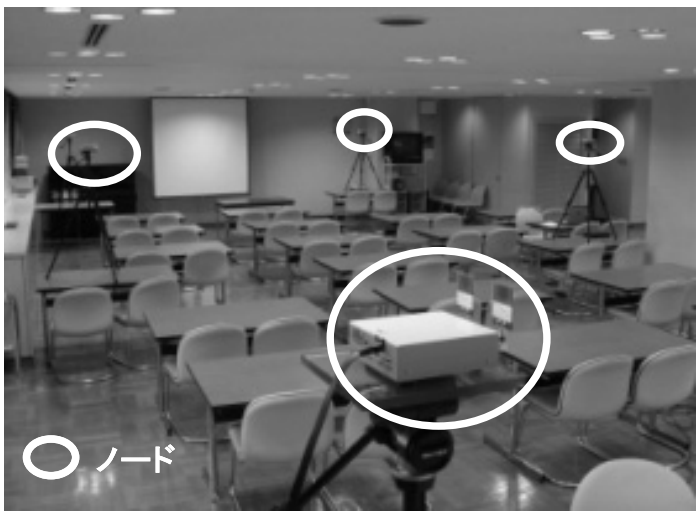

図 8 測位実験の様子

アな鍵配信技術の開発も行われている(10)(11)。

〈3·3〉 位置推定技術 センサネットワークを使用す るシステムにおいて，個々のセンサノードの位置が重要で ある場合が多い。特に移動する人・物に装着されるセンサ ノードでは高い測位精度が要求される。

位置推定技術では，位置が既知の三つの物体からの距離 を測定することによって，対象となる物体の位置を推定す る。無線を使った位置検出方式としては, 受信信号強度を 利用する RSSI (Received Signal Strength Indicator) や電波の 伝播時間を利用する TDOA (Time Difference of Arrival) があ る。

超広帯域無線技術 (UWB:Ultra Wideband) の中でもns オーダの短パルスを使用するインパルス方式では，電波の 到達時間を高精度に求めることが可能であり，高精度な測 位への適用が期待される。藤井らの実験（図 8) では, $12.6 \mathrm{~m}$ $\times 5 \mathrm{~m}$ の範囲内に 6 個の UWB ノードを設置し, その範囲内 に 21 個のタグを置いて精度を測定した結果, $17 \mathrm{~cm}$ 程度の 測位誤差（根二乗平均誤差）で測位可能であったことが報 告されている(12)。

〈3·4〉時刻同期技術多数のセンサノードを収集し

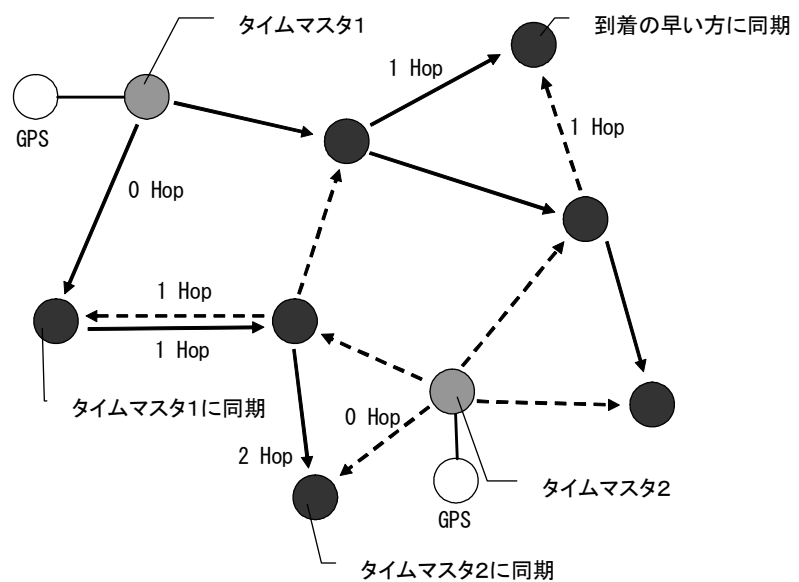

図 9 複数タイムマスタによる分散同期

たデータを関連付けて，意味を持った情報として取り扱う ためには各センサノードの時刻を一致させる必要がある。

また，時刻を高精度に同期させることで，各センサノード に動作タイムスロットを割り当てることで, 通信帯域の削 減，消費電力の削減を行うことが可能になる。

時刻同期技術として一般的に，GPS (Global Positioning System) やNTP (Network Time Protocol) を使用したものが広 く知られているが，無線センサネットワークへの適用につ いては, 前者はコストと消費電力の点で, 後者は無線環境 上での安定性の点で問題がある。

無線センサネットワークの時刻同期技術としては，同期 信号の受信時刻を受信ノード間で交換する RBS (Reference Broadcast Synchronization) $)^{(13)}$ ，時刻管理ノードとセンサノー ド間で往復の通信時刻を交換する $\mathrm{TPSN}^{(14)}$, 時刻と送信遅延 を1フレームに合成した徳永らの手法 ${ }^{(15)}$ がある。RBSやTPSN では 1 回の時刻同期に数フレームを要するが，徳永らの手 法では 1 フレームに抑制することでネットワークへの負荷 を軽減している。また, 多数のセンサノード間で時刻同期 を行うには, 時刻を管理するタイムマスタから各センサノー ドまでの中継数を低減する必要があり, 複数のタイムマス 夕を用いた分散同期が行われる（図 9)。

〈3.5〉通信の高信頼化＼cjkstart無線センサネットワークに おいては，安定した通信を確保する必要がある。このため ZigBee ではマルチホップによるエリアカバー率の拡大と信 頼性向上のための各種ルーティング機能が実装されている。

また，実際にフィールドテストを行い，適用性を事前に 検証することも重要である。図 10 に変電所構内における IEEE802.15.4 規格による無線センサネットワークを用いた ノード位置と受信電力の関係の測定例を示す ${ }^{(16)}$ 。変電所構 内は伝搬路上に金属構造物が多く存在する特殊な環境であ り, 送信ノードと受信ノード間の距離がわずか $10 \mathrm{~cm}$ 程度変 化しても受信電力が大きく低下し，通信が不安定になる場 合があることが分かる。こうした場合には設置後の電波伝 搬特性を測定し，ノード配置を細かく調整するといった作 業もセンサネットワークの高信頼化に必要になる。 


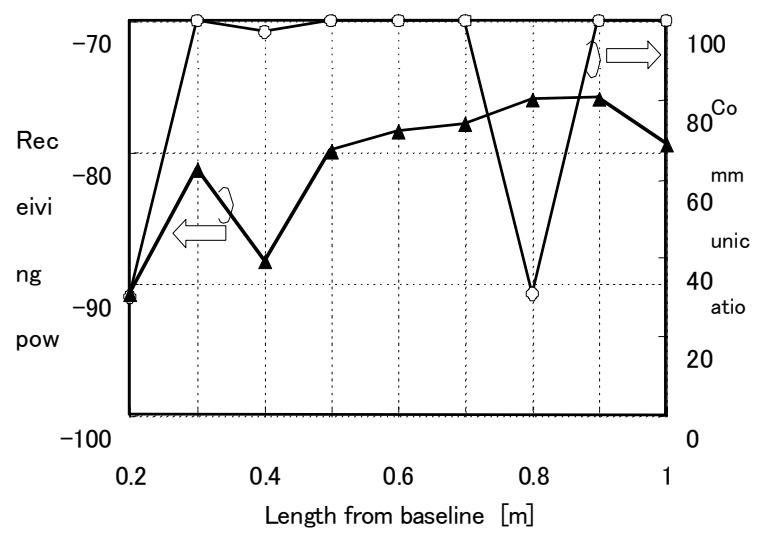

図 10 IEEE802.15.4のノード位置特性例

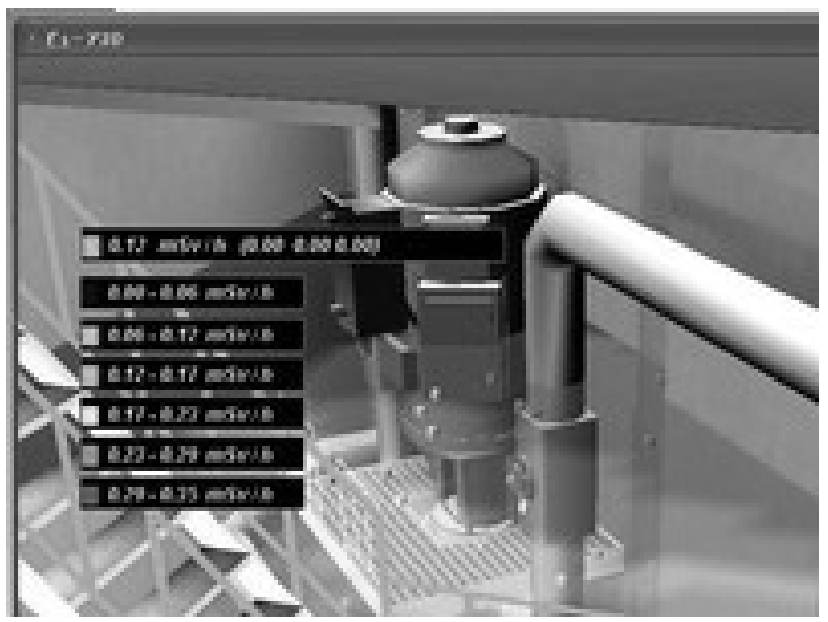

図 11 センサ情報処理の例

(出典 : 原子力発電所用機器の状態監視装置 http://www.jma.or.jp/NDE/ja/details/uunb5796.html)

〈3.6〉情報処理技術センサネットワークが大規模 化するとセンサノードで収集したデータをフィルタリング し，データベース化する技術も必要である。データベース 化によって, 所望のデータパターンで検索する, 時系列モ デル化によって異常予測を行うなど様々な二次利用が可能 になる。

他にも他の情報処理技術と組み合わせることで，収集し たデータをより有効に活用することも試みられている。眓 11 は 2 章で紹介した放射線可視化システムにおけるデータ 処理の例であり, 収集したセンサ情報を作業現場の CG 画像 にカラーでオーバーレイ表示することで本来見えない放射 線を「見える」かのようにしている。

\section{4. 標準化動向}

様々なセンサネットワークが高度に連携し，システムを 高度化していくためには必要に応じてあらゆるところに設 置されたセンサからのデータを利用できるオープン性が必 要であり, そのための相互接続性, 標準化が必須である。

ここでは，センサネットワークに代表的な二つのネット ワーク技術について概要と標準化動向について述べる。

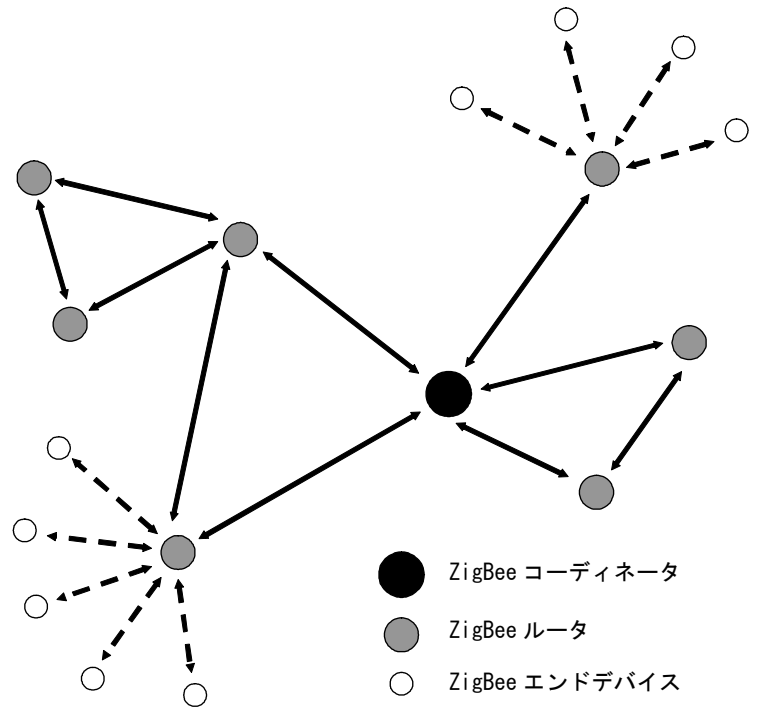

図 12 ZigBee のネットワークモデル

〈4·1〉 ZigBee ZigBee は低消費電力, 低コストを特 長とする最大 $250 \mathrm{kbps}$ の低転送レートの近距離無線ネット ワーク技術である。単三乾電池 2 本で数ヶ月から 2 年程度 動作する低消費電力性と LSI 単価で 2 ドル／チップを目標 とした低コスト性を特徴とする。

PHY レイヤと MAC レイヤの標準化が IEEE802.15.4で, ネットワークレイヤやセキュリティ機能，アプリケーショ ン・インタフェースなどの規格化が ZigBee Alliance で進め られている。

ZigBee Alliance (http://www.zigbee.org/) はZigBee の普及を 推進するための非営利業界団体であり各国から 100 社以上 の企業が参加している。日本国内では ZigBee SIG ジャパン (http://www.zbsig.org/) が普及と仕様の発展を目的に活動を 行っている。

ZigBee 仕様は, 2004 年 12 月に初版が規定され, 2006 年 12 月にZigBee-2006 に改版された。ZigBee ネットワークを 構成するZigBee 論理デバイスは, 役割によって三つに分類 される。ZigBee コーディネータは, ZigBee ネットワークに 一つだけ存在し, ZigBee ネットワーク全体を管理する機能 を持つ。また, ZigBee ルータは, ネットワーク内に複数台 存在することが可能で, データをバケツリレーする機能を 持つ。ZigBee エンドデバイスは, スイッチやセンサなどの 末端デバイス機能を持つ。図 12 に ZigBee のネットワークモ デルを示す。ZigBee ルータがデータを中継することで, 直 接電波が届かないデバイス間でも通信が可能である。また， 途中経路のデバイスが一部停止しても迂回経路によって通 信を継続することができる。

〈4·2〉UWB(Ultra Wideband) UWB は非常に短い幅 のパルスを用い，スペクトルを超広帯域に拡散して通信す る無線方式である。通常の無線通信で広帯域を使用する W-CDMA では占有帯域幅とピーク周波数の比帯域が $1 \%$ 以 下であるのに対し，UWBでは $20 \%$ 以上と超広帯域を利用し ている。センサネットワークへの適用から見た UWB の特徵 
は以下の通りである。

・高速な物理速度でのデータ伝送,

・既存の狭帯域無線との共存,

・マルチパス耐性,

・高性能測距・位置特定,

・回路の簡略化, 小型・低消費電力化。

特にセンサネットワークでセンサノードの位置を特定し ながらセンシングデータを伝送する用途に適した無線通信 方式と言える。

UWB の利用に対する規則整備は，国際電気通信連合の無 線通信セクター (ITU-R) がタスクグループ TG1/8 を設置し, その中の四つの WG で検討が行われた (2002年7月から 2005 年 10 月)。2005 年 10 月に四つの勧告案, (1)UWB の特性 (定 義関係)，(2)UWB から他業務に与えるインパクト（他の無 線システムへの干渉評価), (3)周波数管理フレームワーク (規 則整備関係。米，欧，日本のスペクトルマスクを付録とし て記載)，(4)UWB の測定法（技術基準制定のため)，がとり まとめられたが，UWB利用のための具体的な法制化は各国 に委ねられることになった。

日本においては，2002 年 9 月に総務省情報通信審議会が 情報通信技術分科会 UWB 無線システム委員会を設置し， 2006 年 3 月に技術基準を一部答申（条件付き UWB の導入 許可）した。この一部答申を受け，2006 年 12 月 12 に電波 産業会にて 100Mbps を超える超高速伝送を指向した ARIB STD T91「UWB（超広帯域）無線システム標準規格」が制 定された。測定・試験方法については，テレコムエンジニ アリングセンターが「TELEC-T406 超広帯域無線システムの 無線局に使用するための無線設備の特性試験方法」を制定 した。ARIB STD T91 では, 変調方式は問わない, データレー 卜は 50Mbps 以上，屋内利用に限る，となっている。

一方，アメリカでは，連邦通信委員会 FCC (Federal Communications Commission) が 2002 年 2 月に免許無しでの 民生利用を許可している。規定は，通信・測定用途 (3.1 10.6GHz), イメージング用途 (990MHz 以下, $1.99 \mathrm{GHz}$, $3.1 \sim 10.6 \mathrm{GHz})$, 衝突防止用車載レーダ用途 (22 29GHz) また 屋内，屋外，ハンドヘルドなどに分かれている。

IEEE802 委員会では, IEEE802.15.4 標準 (ZigBee の PHY,MAC) の位置特定精度の向上及び通信距離拡大をねら いとしたセンサネットワーク, RF タグなどへの応用を目的 とした IEEE802.15.4a 標準を 2007 年 3 月に制定した。マイ クロ波帯パルス方式 UWB を用い, 100kbps から 26.03Mbps のデータ伝送速度, $30 \mathrm{~m}$ の通信距離, ALOHA 方式の MAC, TOA (Time of arrival) 方式による $10 \mathrm{~cm}$ オーダ精度の測距 (測 位精度 $1 \mathrm{~m}), 30 \mathrm{~mW}$ 以下の通信時消費電力などを特徵とし ている。上述の ARIB STD T91 規格とは仕様が異なるため, 国内での免許なしでの運用はまだ許可されていないが，今 後のセンサネットワークへの導入が期待される。

\section{5. まとめ}

本稿では, 紙面の関係で詳細な解説を省略した箇所が多々
ある。詳細な解説は末尾の参考文献に譲るので適宜参照し ていただきたい。末筆ながら本解説をまとめるに当たりご 協力頂いたセンサネットワーク調査専門委員会の関係各位 と NTT 未来ねつと研究所の松田和浩氏に感謝申し上げる。

(平成 20 年 7 月 17 日受付)

\section{文献}

（1）平成 17 年度版「情報通信白書」(総務省）「ユビキタスセンサーネッ トワーク技術に関する調查研究会」最終報告 (2004)

（2）阪田史郎・田村陽介：「ユビキタスセンサーネットワーク技術調查報 告書 2004」, インプレス R\&D (2004)

(3) センサネットワーク調查専門委員会編: 「センサネットワークの技術動向 と最新事例」, 電学技報, 第 1112 号 (2008)

(4) 平藤雅之:「フィールドサーバによるユビキタス環境とセンサネットワーク の構築」, 信学会, 第 18 回 回路とシステム軽井沢ワークショップ論文集, pp.175-180 (2004)

(5) NTT 技術ジャーナル 2003 年 10 月号, pp.38-41

(6) http://www.city.kurashiki.okayama.jp/jyoho/intra.html

(7) http://www.yokohama-allergy.org/index.html

(8) http://www.kato-denki.com/alliance/unkoukanri/index.html

(9) S. Yamashita, et al. : "A $15 \times 15 \mathrm{~mm}, 1 \mu \mathrm{A}$, reliable sensor-net module: enabling application-specific nodes", ACM, Proceedings of the fifth international conference on Information processing in sensor networks, pp.383-390 (2006)

(10) 八百健嗣ら:「センサネットワークにおける放送型暗号を用いた鍵更 新方式」，信学会技研報 ISEC2006-140, pp.65-70 (2007)

（11）八百健嗣 - 小沼良平・福永 茂・中井敏久:「センサネットワークに おけるノードの認証管理」, 信学会第 2 種研究会 $\mathrm{CW}$ 研究会 (2007)

(12) 藤井 彰・関口英紀・浅井雅文・倉島茂美 ・落合秀樹 - 河野隆二 : 「IR-UWB 測位システムの開発」, 平 19 信学総大, A-5-9, p.164 (2007)

(13) J. Elson, L. Grid, and D. Estrin : "Fine-Grained Network Time Synchronization using Reference Broadcasts", In Proc. of $5^{\text {th }}$ OSDI (200)

(14) S. Graneriwal , R. Kumar, and M. Srivastava : "Timing sync Protocol for Sensor Networks", ACM SenSys (2004)

(15) 徳永雄一・部 健・西山博仁:「大規模センサーネットワークシステムの 時刻同期手法」, IPSJ Symposium Series Vol.2006, No.6, pp.793-796 (2006)

(16) 尾造宏之:「電波伝搬特性に基づく無線センサネットワーク構築の基 礎検討一変電所構内での微弱無線及び IEEE 802.15.4 の電波伝搬特性 一」, 電力中央研究所報告, R05007 (2006)

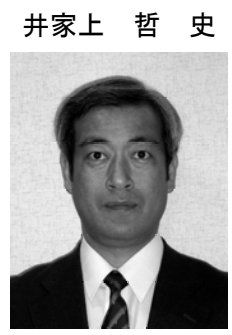

（正員） 1957 年生。1980 年 3 月明治大学工学 部電気工学科卒業。1 1982 年 3 月同大大学院工学 研究科博士前期課程修了。1985 年 3 月同博士後 期課程単位取得。同年郵政省電波研究所入所。 同省通信総合研究所 (名称変更) 鹿島宇宙通信 センター宇宙通信技術研究室長を経て, 1997 年 4 月明治大学理工学部電子通信工学科助教 授。2005 年 4 月同教授, 現在, 理工学部電気電 子生命学科に勤務。この間, 1991 年 10 月から 1992 年 9 月米国イリ ノイ大学アーバナシャンペーン校客員研究員。衛星通信, スペクト 儿拡散通信, 移動通信, UWB 通信などの研究に従事。工博。電子 情報通信学会スペクトル拡散研究専門委員会委員長, 同ワイドバン ドシステム研究専門委員会委員長, 電気学会自営無線の活用技術調 查専門委員会委員長, 同センサネットワーク調査専門委員会委員長 などを歴任。IEEE IWUWBS\&UWBST2004 Technical Program Chair ほか。IEEE Tokyo Section 理事。電子情報通信学会, 情報理論とそ の応用学会, IEEE 会員。 